\title{
EAl Endorsed Transactions

\section{Curriculum development for Educational Technology based on comparisons of course syllabi resources using lexical analysis}

\author{
Minoru Nakayama ${ }^{1, *}$, Katsuaki Suzuki ${ }^{2}$, Chiharu Kogo ${ }^{3}$, Maomi Ueno $^{4}$ \\ ${ }^{1}$ School of Engineering, Tokyo Institute of Technology, Ookayama 2-12-1, Meguro, Tokyo, 152-855, Japan \\ ${ }^{2}$ Graduate School of Social and Cultural Science, Kumamoto University, Kurokami 2-40-1, Chuou-ku, Kumamoto, \\ 860-8555, Japan \\ ${ }^{3}$ Faculty of Human Science, Waseda University, Mikajima 2-579-15, Tokorozawa, 359-1192, Japan \\ ${ }^{4}$ Faculty of Informatics and Engineering, University of Electro-Communications, Chofugaoka 1-5-1, Chofu, 182- \\ 8585 Japan
}

\section{Abstract}

Current open education resources and the existing online learning environment require appropriate human resources, such as designers and developers, and the technical standards required for these platform to operate and be maintained. Though these resources have been developed at various universities, a standard for course curriculum has not yet been established. To identify content commonly taught in human resource development courses, the interactions between course syllabi at the post graduate level are examined using a combination of lexical analysis and cluster analysis. In the results, some fundamental information and features usable in curriculum for both educational technology and learning technology courses was gathered.

Received on 4 December 2017; accepted on 12 December 2017; published on 19 December 2017

Keywords: Syllabus, Technology enhanced learning, human resource development

Copyright () 2017 Minoru Nakayama et al., licensed to EAI. This is an open access article distributed under the terms of the Creative Commons Attribution license (http://creativecommons.org/licenses/by/3.0/), which permits unlimited use, distribution and reproduction in any medium so long as the original work is properly cited.

doi:10.4108/eai.19-12-2017.153487

\section{Introduction}

Various educational systems, including specialised educational programs, are currently used for the broad objectives of developing academic performance and practical experience. Since the structures of most systems are not simple and require large investments of time and money, appropriate course design and assessment should be conducted in advance $[5,12]$. To meet these goals, specialised expertise and speedy development of the necessary human resources needed for each project are necessary. Though educational systems such as MOOCs (Massive Open Online Courses), and evaluation techniques such as learning analytics are currently being introduced as an area of educational technology throughout the world, most courses at universities are developed independently, and there is little interest in organised collaboration

*Corresponding author. Email: nakayama@ict.e.titech.ac.jp
$[8,9]$. In other fields of research, such as computer science, each university offers their own courses, though all courses use a common curriculum [7, 10]. The curriculum standard is updated periodically, and is sharable [13]. Therefore, common knowledge or prototypes of educational technology curricula should be summarised in order to maximise the effectiveness of every educational technology course.

The authors have been using lexical analysis $[8,9]$ to analyse course syllabi at several universities around the world. In regards to results of these analyses, a possible format for curriculum development is discussed in this paper. This paper presents the following topics.

The purpose of this paper is to use lexical analysis to extract common knowledge from several curricula related to educational technology and learning technology, including technologically enhanced learning. In addition to this, the stigmatisation of sharable curriculum content may encourage wider distribution of 
educational technology and learning technology knowledge.

\section{Method}

\subsection{Syllabi for Educational Technology and Technology Enhanced learning}

Four types of document sets were selected: a standard curriculum which uses a top-down approach, a summarised core curriculum for the major courses, a syllabus of hybrid courses which involve education and human-computer interaction, and a number of Japanese documents in these topics. The structures of these syllabi were compared and examined. The details of the information resources are as follows:

AECT curriculum standards. A curriculum standard for educational communication technology which was developed by the AECT (Association for Educational Communication Technology) was created using a top-down approach involving Design, Development, Utilisation, Management and Evaluation, with subdomains for each of these also being explained [1]. The syllabus for every sub-domain has been well described and is summarised from topics in the related areas. Courses at many universities have been created according to this standard.

Learning Technology courses in the UK. Five degree courses in Learning Technology at British universities were selected using a bottom-up approach type of evaluation concerning the information of an ALT association (the Association for Learning Technology) $[2,8]$.

The course curriculum consisted of core subjects and electives. The texts of syllabi for every core curriculum were analysed, and four clusters were extracted: design, learning technology, practice-based research and research methodologies [8]. Electives were also analysed in the same way, and three additional categories were extracted: digital environment, online learning, and educational issues.

$\mathrm{HCl}$ contribution to Learning Technology. A hybrid course, which covers human-computer interaction (HCI) and psychology, such as the Masters of Educational Technology and Applied Learning Science (METALS) course at Carnegie Mellon University (CMU) [3], was analysed. The curriculum consists of an overview of online learning and research projects. The electives include education and learning science, human centred computing, user interface and applied cognitive sciences courses. As mentioned in the Introduction section, some of current demands for educational technology are the systematic development of the learning environment and the measurement and assessment of technical procedures throughout the world. In a sense, this curriculum is a prototype developed in response to these requests.

Japanese contributions to educational technology. The Japanese academic society JSET (Japanese Society of Educational Technology) published a series of books summarising current research activity, instead of creating a curriculum standard. There are a few postgraduate courses in educational technology. To summarise resource information regarding instructional materials in Japanese educational technology courses, the tables of contents of 6 textbooks, which were approved by the academic society of educational technology such as JSET, were analysed. They are both recent publications in Japan. These books are titled as follows:

- Research methodology

- Educational system development

- Practice based research

- Classroom lesson study

- Educational media design

- Educational evaluation

The main topics were educational practice and lesson study, which have been established as teacher training and teacher development.

\subsection{Curriculum comparison using lexical analysis}

To illustrate the conceptual structure of the course syllabi, a lexical and cluster analysis was conducted using the following procedure.

All documents were analysed morphologically, and all nouns were then extracted. A term-document matrix was created for every syllabus using the term frequencies. Using these features, cosine similarity values between term frequency vectors were calculated, and cluster analysis was conducted using the similarities as an index of distance (the range is 0 to 1.4). This analysis was conducted using a text-based comparison, and thus it should be noted that some interpretations were influenced and depended on the text descriptions.

\section{Results}

\subsection{Relationships between information from curricula}

Though four document sets show their characteristics, there are few common topics, such as research methodology. The benefit of the current situation is that it enhances the diversity of this area of study, though misconceptions may arise due to the international nature of its collaboration. Current demands, such as the promotion of open educational resources, require experts in information technology and educational 


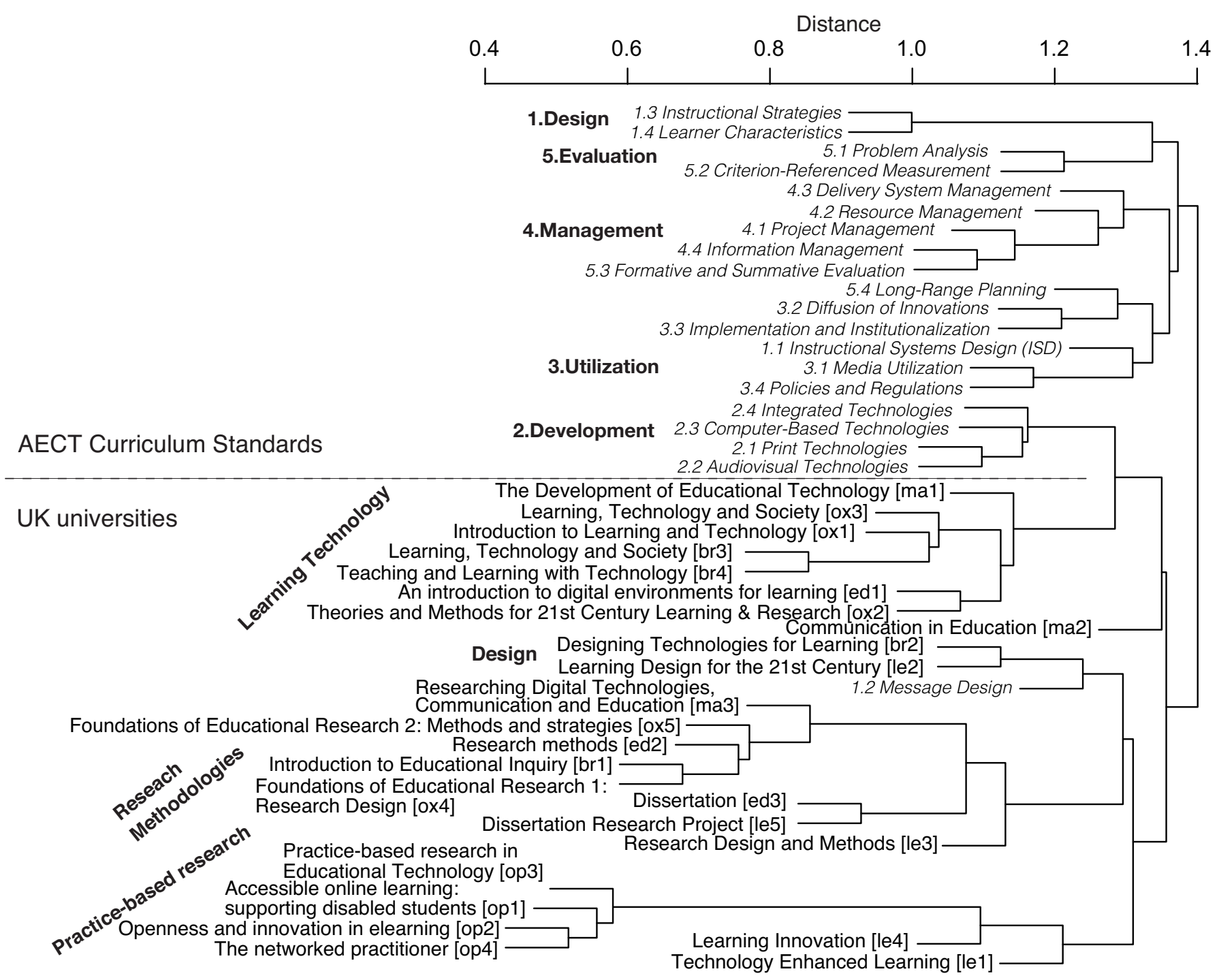

Figure 1. A dendrogram of subjects which are described as sub-domains of AECT curriculum standards and syllabi at UK universities.

technology, or experts in instructional design and cognitive science may be necessary in order to develop improved policies.

The results of analyses reveal some interactions between the two existing curricula, and are summarised as follows.

AECT curriculum and UK university courses. As mentioned in the method section, the structure of courses is different between AECT curriculum standards and core courses of UK universities. Figure 1 shows a dendrogram which confirms the interactions. Most subdomains of AECT curriculum are located in the upper panel, and most courses of UK universities are located in the lower panel. The dendrogram suggests that the two curricula are mostly independent, except "Message Design", since the two curricula were originally created for "education and communications technology" courses and "learning technology" courses, respectively. This similarity exists between the topics: "Development" in US-AECT and "Learning Technology" in UK university courses.

Fundamentally, two sets of syllabi were summarised in different ways using top-down or bottom-up approaches. The dendrogram shows that the concepts are also independent, as these topics cover a broad range of educational technology and learning technology.

CMU-METALS and $\mathrm{HCl}$ courses. The course curriculum of CMU-METALS, an HCI and psychology hybrid course, may contribute to current open education and online learning activity in regards to its scope. To verify this concept, the overlapping condition was confirmed using the same procedure as in Figure 1. 


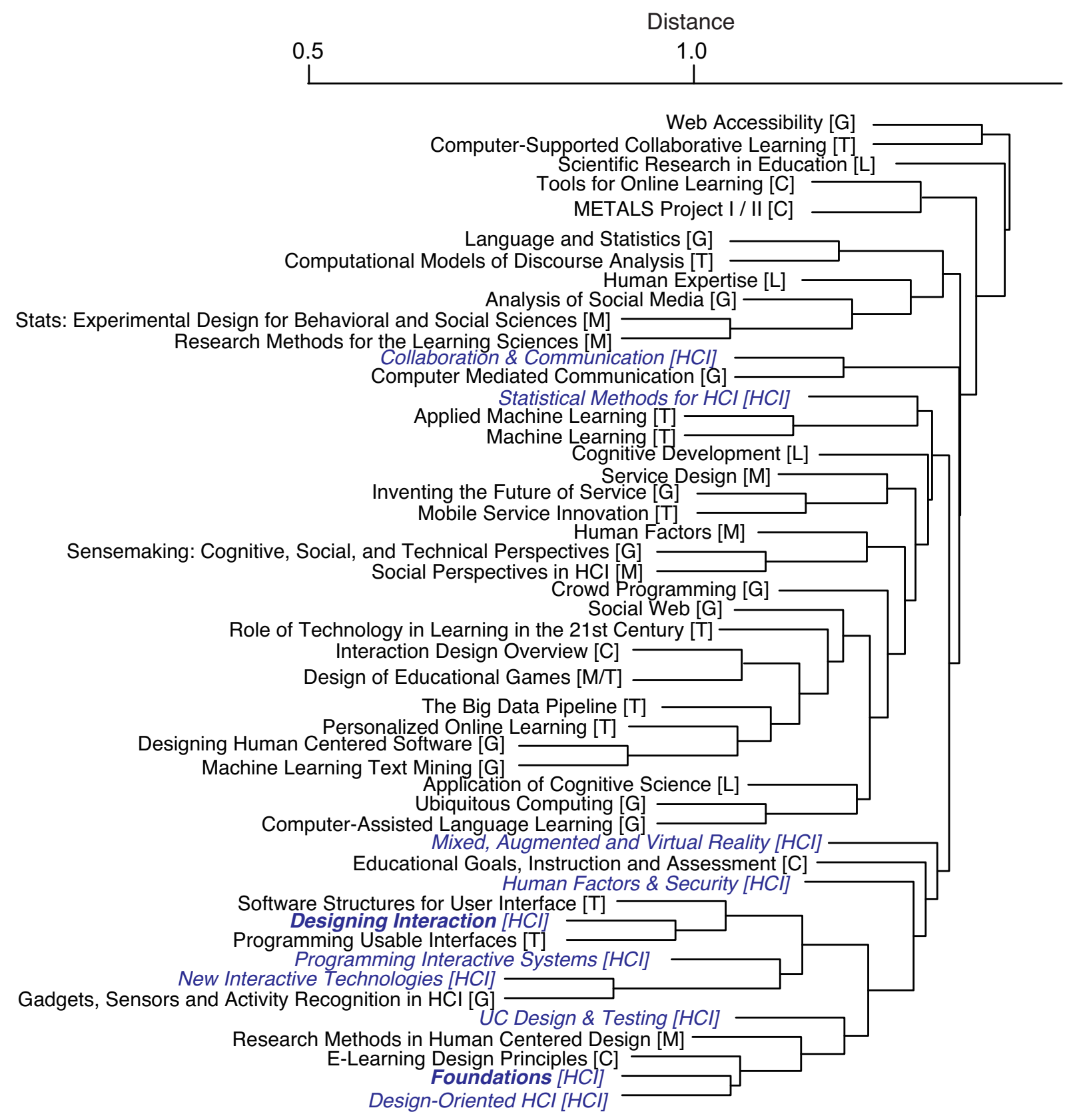

Figure 2. A dendrogram of $\mathrm{HCl} B O K s$ and subjects which are described as syllabi at CMU-METALS ([C]:Core, [T]:Technology, [L]:Learning Sciences Theory \& Industrial Design, [M]:Methods \& Design, [G]:General Electives).

The dendrogram in Figure 2 summarises the results. Here, HCI BOKs (BOK: Body of Knowledge) are illustrated in blue. As they are distributed across the dendrogram, implementation of the HCI concept in the course is confirmed. The results confirm with accuracy that the common content of syllabus texts are most certainly indicated in the same clusters, as Figure 2 shows.

Some contents of CMU-METALS and AECT standards or CMU-METALS and UK university courses were shared. The curricula lists various topics, such as human computer interaction, system development and learning analytics, which include machine learning and text mining, big data pipelines and others. The design and analysis of learning activities in an open educational environment may require this knowledge and these techniques. These points should be considered carefully in a future study. 


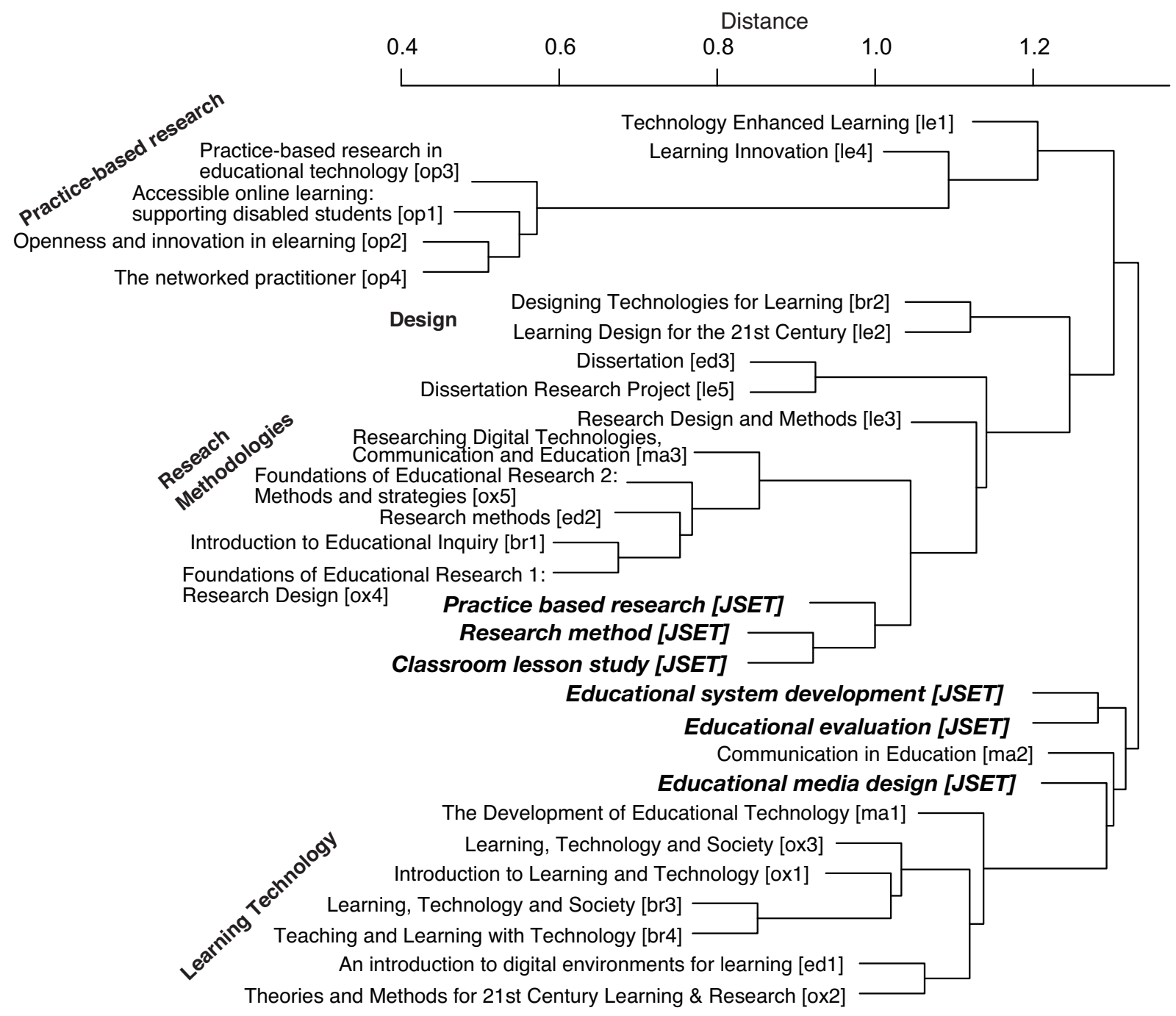

Figure 3. A dendrogram of subjects which are described as syllabi at UK universities and contents of books published by JSET.

Courses at UK universities and book contents of JSET. Some courses on practice-based research in educational technology are provided at one UK university. Lesson study [6], which is one of the practice-based research topics that improves instructional methods in teacher learning communities, is a major topic of Japanese Educational Technology. Therefore, some common topics may be expected between courses at UK universities and topics of Japanese educational technology.

A dendrogram between UK courses and Japanese topics is illustrated in Figure 3. Though there are some common topics between the two concepts, the topics for both practice-based research and classroom lesson study for JSET are summarised as a research methodology. Other topics in JSET, such as educational system development or educational evaluation and media design, are almost always independent in courses at UK universities, although they are connected to topics which concern learning technology. The results also show that between the two concepts, there are topics which use different approaches.

\subsection{Discussion}

As mentioned in the above sections, there are many courses with both educational technology and learning technology content. Though this content is widely diverse, some of it may contain common concepts used in topics such as the components of learning technology, or in research methodologies.

On the other hand, some of the CMU-METALS courses consist of human-computer interaction topics, then BOKs of HCIs, which are defined and standardised by the joint task force [13], are certainly included. This indicates that the framework of the curriculum standards is particularly significant. 
Recently, the opportunities for learning using online materials have increased gradually, so development and delivery of both technical and learning design aspects are also necessary. A committee of Learning Technology Standards for technical infrastructure issues was established and is actively working on the standardisation of learning materials. Learning design issues and the development of human resources for this topic of study is another aspect that should be considered immediately, in regards to the future of learning flexibility and technology enhanced learning systems.

\section{Curriculum development}

As a purpose of this study is to create a common curriculum for educational technology, learning technology, and technology enhanced learning courses. Various resources were analysed, and the relationships between these were examined. A new curriculum content at the master's course level was introduced using the resources mentioned above and the additional information required [11]. The procedure is as follows.

The curriculum can be used to develop significant human resources in order to study (and develop topics of study) and resolve current educational issues, including those in sectors such as industry and business.

The curriculum covers three courses by taking into account the requirements mentioned above in elective sub-courses, as follows:

1. Human development: teacher education/training, inhouse education/training, life-long learning

2. System development: e-learning, e-testing, eassessment

\section{Educational development}

In addition to the information about curricula and courses mentioned above, the Japanese domestic courses have also been included as a resource as most participants are practitioners in the areas of higher education or social services, and have studied instructional sciences.

\section{AECT Curriculum Standard $[1,7]$}

2. Core courses for Learning technology at UK universities [2, 7]

3. CMU METALS(Human-computer interaction and Psychology) [3]

4. Course syllabus, Instructional Sciences at Kumamoto University [4]

All authors discussed and developed a possible curriculum, as shown in Table 1. The course contents consist of elementary and advanced levels. The table indicates the level, course name (subject), electives for sub-courses, and key words for the courses, from left to right.

In addition to "Pedagogical fundamentals", some courses were selected as fundamentals of educational study, such as "Instructional design", "Learning assessment and measurement theory", and "Educational statistics" during the discussions. Also, research methodologies and practice exercises for learning systems are fundamental.

Recently, issues regarding e-learning, in particular "e-testing" and "Learning analytics", have become key pieces of knowledge, and are required in both academic and industrial sectors. By taking into account the concepts and courses of METALS [3], the curriculum enhances information science course subjects, in order to train human resources in systems development.

Conventional educational technology topics, such as teacher training and classroom lesson study are enhanced for "Human resource development" and "Educational management".

The curriculum is initially designed for Master's level courses. Therefore, the development of academic experts will be a topic of our further study. Also, instructional strategy and assessment methodology should carefully be developed further. The additional question is how to deliver courses to learners and practitioners beyond the conventional university teaching system, as there are few courses in educational technology at Japanese universities.

Of course, the presented curriculum may be insufficient to be a standard curriculum for educational technology since the curriculum development has been discussed based on a few current curricula in US and UK. Generally, all curriculum should be revised periodically in considering the validity and the effectiveness. The impacted curricula around the world also should be considered to generate a standard curriculum. They will be a subject of our further study.

\section{Conclusions}

This paper examined the relationships between typical course curricula, in order to create a sharable curriculum for human resource development in the field of educational technology.

The analyses produced the following results.

1. The relationships across contents of courses which are components of the curriculum are mutually compared, and the diversity of curriculum formations was confirmed.

2. The results suggest that the major contents of Japanese educational technology courses consists 
Table 1. A proposed curriculum for Educational Technology

\begin{tabular}{|c|c|c|c|c|c|}
\hline Level & Courses & C1 & $\mathrm{C} 2$ & C3 & Keywords \\
\hline Elementary & $\begin{array}{l}\text { Introduction to Educa- } \\
\text { tional Technology } \\
\text { Pedagogical fundamen- } \\
\text { tals } \\
\text { ID: Elementary } \\
\text { ID: Advanced } \\
\text { Learning assessment and } \\
\text { measurment theory } \\
\text { Educational statistics } \\
\text { Cognitive psychology } \\
\text { Computer Algorithms } \\
\text { Educational system } \\
\text { Learning Sciences } \\
\text { Practice exercises for } \\
\text { learning systems } \\
\text { Research methodology I } \\
\text { Research methodology II }\end{array}$ & $\circ$ & $\begin{array}{l}0 \\
\circ\end{array}$ & $\begin{array}{l}0 \\
\circ\end{array}$ & $\begin{array}{l}\text { Backgrounds, Basic theories, Psychology, Informatics, Pedagogy } \\
\text { Educational philosophy, Educational methodology, Educational } \\
\text { psychology } \\
\text { Design of educational materials, evaluation of educational } \\
\text { materials, ID process } \\
\text { Needs analysis and systematization, analysis of environmental } \\
\text { factors, instructional system design } \\
\text { Learning assessment, psychometrics } \\
\text { Statistical hypothesis tests, Multivariate analysis, Structural } \\
\text { equation modeling, Meta analysis } \\
\text { Memory and learning, Mental model, Motivation, Learner's } \\
\text { characteristics, Collaborative learning } \\
\text { Computing algorithms, Data structure, Graph, Search tree } \\
\text { Learning environment, Learning support system, LMS, Learning } \\
\text { portfolio } \\
\text { Collaborative learning, Memory and knowledge, Problem } \\
\text { solving, Inference, Meta cognition, Self-regulated learning } \\
\text { Learning material production, Educational practice, Educational } \\
\text { management } \\
\text { Experimental design, Questionnaire method, Semi-structured } \\
\text { interview } \\
\text { Thesis writing, Literature search, Design experimental approach, } \\
\text { Ethnography }\end{array}$ \\
\hline Advanced & $\begin{array}{l}\text { e-learning } \\
\text { ID: Development } \\
\text { Media design for learn- } \\
\text { ing } \\
\text { Educational } \\
\text { management } \\
\text { Human Resource Devel- } \\
\text { opment } \\
\text { e-Testing } \\
\text { Machine learning } \\
\text { Cognitive processing } \\
\text { Learning Analytics }\end{array}$ & $\circ$ & $\begin{array}{l}\circ \\
\circ\end{array}$ & $\begin{array}{l}\circ \\
\circ\end{array}$ & $\begin{array}{l}\text { Online learning materials, Online discussion, peer review, } \\
\text { gamification } \\
\text { Techniques for overall design and management of instructional } \\
\text { systems } \\
\text { Multi-modal system, Human information processing, Character- } \\
\text { istics of media, Human Computer Interaction } \\
\text { Educational development, Educational management, Lesson } \\
\text { study } \\
\text { Teacher training, In-service training, Life long learning, Faculty } \\
\text { development } \\
\text { Test theory, Item Response theory, Reliability, Validity } \\
\text { Prediction, Estimation, Supervised/Non-supervised learning, } \\
\text { Data mining } \\
\text { Modeling of learning, Learning support system } \\
\text { Integrated analysis for learning records, Data visualization }\end{array}$ \\
\hline
\end{tabular}

C1:Human resource development, C2:System development, C3:Educational development

ID:Instructional design

of research methodologies and learning technology topics.

In regards to the results of analyses of the courses presented a new curriculum was proposed. The curriculum presents elementary and advanced courses in order to develop three types of human resources for educational technology, namely "Human resource development", "Educational systems", and "Educational development".
Since experts are few and the number of university departments offering these courses may be limited, collaboration between researchers at multiple universities should be encouraged. Some courses which have been provided via MOOCs have assisted practitioners in a variety of $\mathrm{HCI}$ industrial sectors [7]. A collaborative network or association is required to distribute courses based on this curriculum, and to assess learners who have completed courses.

Also, curriculum revisions and extensions in referring impacted curricula should be considered to create 
a standard curriculum. These preparations are topics which will require further investigation in the future.

Acknowledgement. This research was partially supported by the Japan Society for the Promotion of Science (JSPS), Grantin-Aid for Scientific Research (KAKEN, 15K12405, 20152016).

This paper is an extended version which is based on reports at a workshop of AVI2016 [8] and ITHET2016 [9]. The authors would like to thank those who provided useful comments regarding both of these papers.

\section{References}

[1] AECT (Association for Education and Communication Technology) Curriculum Standards. URL http: / / www . aect.org/standards/initstand.html (accessed on 27 May 2015).

[2] Alt(Association for Learning Technology) TEL Courses. URL http://wiki.alt.ac.uk/index.php/ TEL_Courses (accessed on 26 May 2015).

[3] Carnegie Mellon University MetalS. URL http: // metals.hcii.cmu. edu (accessed on 5 Jan 2016).

[4] Garaduate School of Instructional System, Kumamoto University Curriculum - Master's Program. URL http://www.gsis.kumamoto-u.ac . jp/curriculum/masters-prgram/ (accessed on 25 Jun 2015).

[5] Hill, P. (2012) Online educational delivery models: A descriptive view. Educause review November/Dcember: 85-97.

[6] Lewis, C.C. and Hurd, J. (2011) Lesson study - step by step (Portsmouth, NH: Heinemann).
[7] Nakayama, M. (2015) Current topics for hci course design with a computer science curriculum. In Proceedings of 19th International Conference on Information Visualisation: 255-258.

[8] Nakayama, M. (2016) Creating educational technology curricula for advanced studies in learning technology. EAI Endorsed Transactions on Ambient Systems 3: e4,1-4.

[9] Nakayama, M. (2016) Lexical analysis of syllabi in the area of technology enhanced learning. In Proceedings of 15th International Conference on Information Technology Based Higher Educationa and Training (ITHET): 1-5.

[10] Nakayama, M. and Hascoët, M. (2014) Variations of "human computer interaction" syllabus in computer science area. In Proceedings of 18th International Conference on Information Visualisation: 382-385.

[11] Nakayama, M., Suzuki, K., Kogo, C. and Ueno, M. (2016) A curriculum for human resource development in Educational Technology. In Proceedings of the 32nd JSET annual conference: 435-436.

[12] Shelton, B.E., Duffin, J., Wang, Y. and Ball, J. (2010) Linking OpenCourse Wares and open education resources: creating and effective search and recommendation system. Procedia Computer Science 1: 2865-2870.

[13] The Joint Task Force on Computing Curricula, Association FOR COMPUTER Machinery AND IEEE CS (2013) Computer science curricula 2013 - curiculum guidelines for undergraduate degree progurams in computer science. URL http://ai. stanford.edu/users/sahami / CS2013/final-draft/ CS2013-final-report.pdf (accessed on 15 July 2015). 